\title{
ESTIMATION OF THE CARRYING CAPACITY OF YANGTZE FINLESS PORPOISE (Neophocaena asiaeorientalis asiaeorientalis) IN TIAN-E-ZHOU OXBOW BASED ON LINEAR FOOD NETWORK MODEL
}

\author{
LI, Y. T. ${ }^{1,2,3}-$ WANG, D. ${ }^{1 *}$ \\ ${ }^{1}$ Key Laboratory of Aquatic Biodiversity and Conservation of the Chinese Academy of Sciences, \\ Institute of Hydrobiology, Chinese Academy of Sciences, Wuhan 430072, China \\ ${ }^{2}$ University of Chinese Academy of Sciences, Beijing 100039, China \\ ${ }^{3}$ Yellow Sea Fisheries Research Institute, Chinese Academy of Fishery Sciences, Qingdao \\ 266071, China \\ *Corresponding author \\ e-mail:wangd@ihb.ac.cn \\ (Received $11^{\text {th }}$ Aug 2020; accepted $17^{\text {th }}$ Sep 2020)
}

\begin{abstract}
A food network model of the Tian-E-Zhou Oxbow ecosystem in the Yangtze River was established by combining fishery resource data with other aquatic biological data. The ecosystem can be divided into seven discrete trophic levels, and nutrient flow occurs mainly between the trophic levels I-V. The average material transfer efficiency of each trophic level was $10.5 \%$, there were no obvious key species in the system, and large aquatic plants had the largest key index $(-0.173)$. The matter and energy recirculation ratio in the system was low, while the values of other indicators such as system connection index (CI), system omnivore index (SOI), Finn's cycle index and Finn's mean path length were all at a low level, indicating that the Tian-E-Zhou Oxbow ecosystem was at an early stage of development. Finally, based on the food network model, the environmental carrying capacity of the Yangtze finless porpoise in the Tian-E-Zhou Reserve was calculated as $0.207 \mathrm{t} / \mathrm{km}^{2}$, counting about 89 individuals.
\end{abstract}

Keywords: ECOPATH with ECOSIM, trophic modeling, energy flow, food web, ecosystem

\section{Introduction}

Capacity originates from the logistic equation of population ecology. It was originally a term in animal husbandry management and has now become an important concept in wildlife management. Leopold (1933) was the first to propose the definition of capacity to be the maximum number of wild animals allowed to survive in an environmental condition. Later, a number of scholars successively proposed the definition of tolerance. For example, Edwards et al. (2013) defined the capacity as the maximum population quantity that can be obtained in the habitat under the environmental conditions favored by the animals within a specific time interval (usually 1 year) without the occurrence of ecosystem degradation and damage to animal quality. Over the years, the carrying capacity concept has been used to describe the growth limits of natural populations, account for resource use by rising human populations and make environmental management decisions (Chapman and Byron, 2018). Animals exist in specific habitats, and changes in habitat conditions will directly or indirectly affect the survival and reproduction of these animals and the sizes of the populations. Therefore, the carrying capacity is not a long-term stable value and will change with changes in various 
ecological factors in the habitat. It becomes a relative constant only for a specified period (Storch and Okie, 2019).

ECOPATH is a mass-based, static, and ecosystem-based model that takes all trophic levels of the ecosystem into account and is mainly used to simulate ecosystem status and internal energy flows (Zhu et al., 2020). Researchers have evaluated carrying capacity through the ECOPATH model based on the assumption that the carrying capacity value is reached when the population increase made the model unbalanced (Byron et al., 2011; Ferreira et al., 2018). This approach represents an advance in that it places the organism at an ecosystem level to assess the carrying capacity. ECOSIM allows for the temporal exploration of potential impacts of a further increase in population based on dynamic species interaction, and has been used for carrying capacity evaluation (Gao et al., 2018; Outeiro et al., 2020).

The Tian-E-Zhou Oxbow is an ex-situ reservation. Five Yangtze finless porpoises (Neophocaena asiaeorientalis asiaeorientalis) were moved there in 1990. After years of development, a population of about 60 finless porpoises was present in the site in 2015 (2015 census data). The water area of the Tian-E-Zhou Oxbow has shrunk in recent years due to climate change and the development of the surrounding shoals. In addition, the water quality in the oxbow has been deteriorating. It is, therefore, necessary to calculate whether the population of the Yangtze finless porpoise has reached the saturation state. If the population density is too high, measures should be taken to improve the habitat. Therefore, the assessment of carrying capacity is of vital importance for both species protection and habitat protection in the reserve.

In order to achieve this goal, we built a nutrition ecosystem network channel model (ECOPATH) in Tian-E-Zhou Oxbow with Yangtze finless porpoise population, fishery resources survey database, and other aquatic biological resources survey data. The ecosystem characteristics and energy flow regularity of the Tian-E-Zhou Oxbow were systematically analyzed, the carrying capacity of the Yangtze finless porpoise was estimated and the main factors affecting the carrying capacity were analyzed.

\section{Materials and Methods}

\section{Study area}

The Tian-E-Zhou Oxbow $\left(112^{\circ} 31^{\prime}-112^{\circ} 37^{\prime} \mathrm{E}, 2^{\circ} 46^{\prime}-29^{\circ} 51^{\prime} \mathrm{N}\right)$ is located on the northern bank of the Yangtze River about $20 \mathrm{~km}$ downstream of Shishou City, Hubei Province, central China (Fig. 1). It is oxbow shaped and was originally the main channel of the Yangtze River. It was formed by the natural cutting and straightening of the Yangtze River in 1972. The oxbow is $20.9 \mathrm{~km}$ long, with a water surface width of 0.2-1.5 km, average water depth of $4.5 \mathrm{~m}$, and a total area of about $20 \mathrm{~km}^{2}$.

\section{Model description}

In this study, the ECOPATH method was used to construct the nutrition network model in the Tian-E-Zhou Oxbow ecosystem. This method was originally proposed by Polovina (1984) of the Hawaii Institute of Oceanography in the United States and was used to describe the biological production and food digestion processes of aquatic ecosystems in a stable state. Subsequently, combined with the ecological theory of energy analysis of Ulanowicz (1986), it gradually developed into a method of quantitative analysis of ecosystem structure and function. 


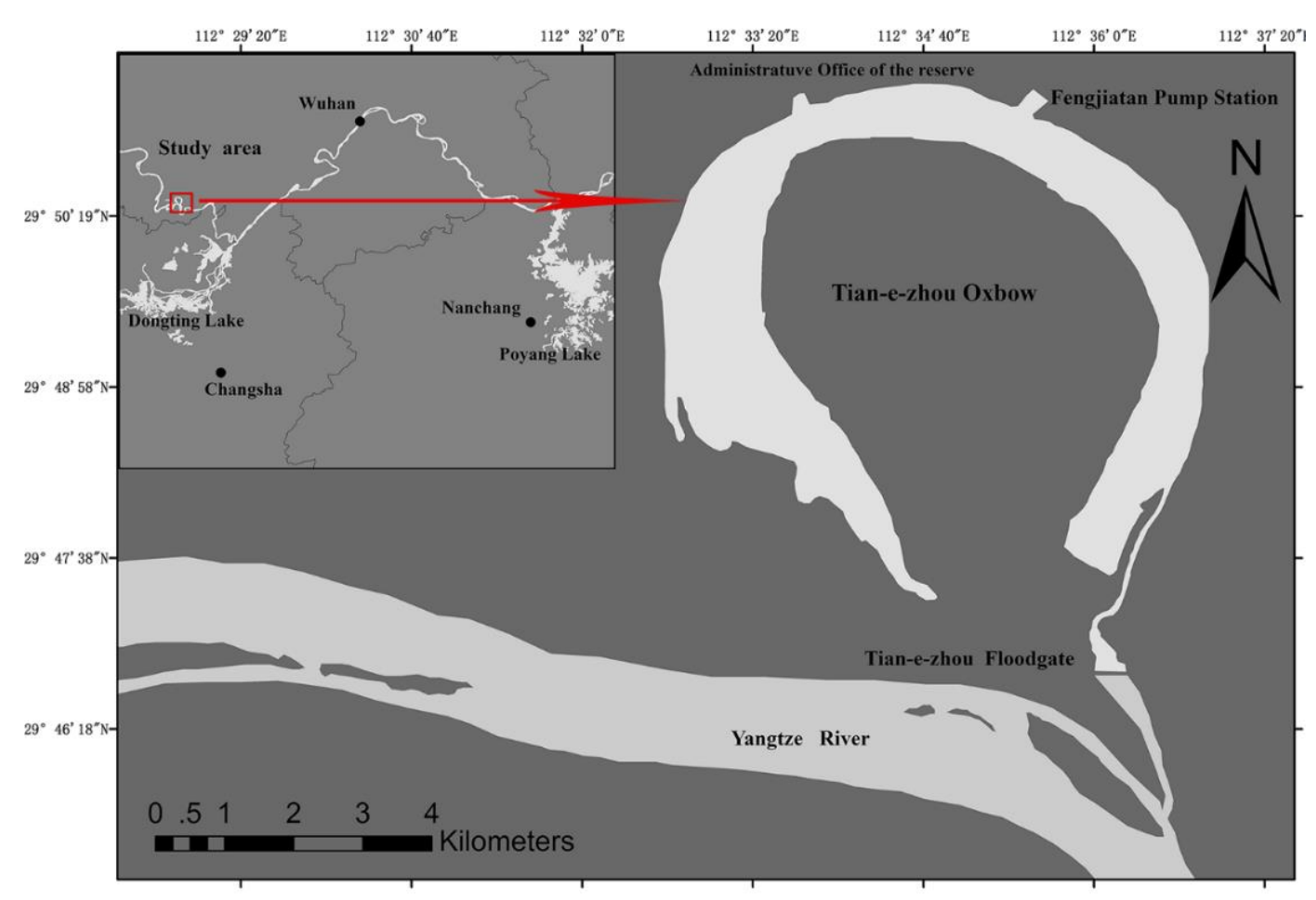

Figure 1. Location of the study area

The ECOPATH model defines that an ecosystem is composed of a series of ecologically related functional groups, all of which can combine to cover the process of energy flow in an ecosystem. The model assumes that the energy input and output balance of each functional group can be described by the following formula (Christensen et al., 2008):

$$
B_{i} \times(P / B)_{i} \times E E_{i}-\sum_{j=1}^{n} B_{j} \times D C_{j i}-Y_{i}-B_{i}=0
$$

In type, the $(\boldsymbol{P} / \boldsymbol{B})_{i}$ is the ratio of functional group i production and biomass, $(\boldsymbol{Q} / \boldsymbol{B})_{j}$ for predation function group $\mathrm{j}$ consumption and the ratio of biomass, $\boldsymbol{D} \boldsymbol{C}_{\boldsymbol{j} i}$ prey for functional groups of the predator functional group $\mathrm{j} I$ always prey on quantity proportion, $\sum_{j=1}^{n} B_{j} \times(Q / B)_{j} \times D C_{j i}$ on behalf of the functional groups were all in the amount of functional groups feeding.

The ECOPATH model needs to input the basic parameters including biomass $\boldsymbol{B}_{\boldsymbol{i}}$, biological turnover ratio $(\boldsymbol{P} / \boldsymbol{B})_{\boldsymbol{i}}$, consumption and biomass ratio $(\boldsymbol{Q} / \boldsymbol{B})_{\boldsymbol{i}}$, the ecological efficiency of $\boldsymbol{E} \boldsymbol{E}_{\boldsymbol{i}}$, food nutrition matrix $\boldsymbol{D} \boldsymbol{C}_{\boldsymbol{j} \boldsymbol{i}}$ and total catches a $\boldsymbol{Y}_{\boldsymbol{i}}$. Any one of the first four parameters can be unknown. The other parameters are calculated by the model, but $\boldsymbol{E}_{\boldsymbol{i}}$ is the best to have as an unknown quantity, because the parameters are difficult to measure directly. The latter two parameters, namely food composition $\boldsymbol{D} \boldsymbol{C}_{\boldsymbol{j} \boldsymbol{i}}$, and catch quantity $\boldsymbol{Y}_{\boldsymbol{i}}$, require input.

The results of the biomass and ecological network analysis indicators total system throughput (TST) (Ulanowicz, 2012), biomass, primary production, respiration, transfer efficiency (Christensen and Walters, 2004), Connectance index, Finn's cycling index 
(Finn, 1976), system omnivory index and Finn's mean path length were downloaded from ECOSIM and ECOSIM network analysis in ECOPATH (Christensen et al., 2005; Behera et al., 2020).

\section{The data source}

In this study, the biomass data of finless porpoises were obtained from the population census in 2015. Fish data were obtained from the fish catch and hydroacoustic survey in October 2014, and the other data were obtained from the biological resources survey of the reserve in 2011 as well as published literature and scientific investigation reports on the Tian-E-Zhou Oxbow (e.g., Wang et al., 2012; Sun et al., 2013; Ma et al., 2014).

\section{Functional group division}

First, the main biological groups or species in the Tian-E-Zhou Oxbow ecosystem were divided into 18 functional groups according to their biological and ecological characteristics, namely, classification status, nutritional type, individual size, and the water layer they occupied (Christensen et al., 2005; Guo et al., 2013; Li et al., 2018). Species of significant ecological or economic value that needed to be analyzed separately were treated as functional groups for easy study. See Table 1 for the names of each functional group and the main categories it includes. Among them, the detrital functional group was necessary to construct the nutrition network model. The two functional groups of large aquatic plants and phytoplankton belong to the primary producers, while the remaining 15 functional groups are all consumers, covering the primary consumers, secondary consumers, and top consumers. The defined 18 functional groups can cover the entire process of energy flow in the oxbow ecosystem.

Table 1. Classification of functional groups within Tian-E-Zhou Oxbow ecosystem

\begin{tabular}{c|c|c}
\hline Number & Functional group & Species composition \\
\hline 1 & Finless porpoise & Neophocaena asiaeorientalis asiaeorientalis \\
2 & Snakehead fish & Channa argus, Siniperca chuati \\
3 & Topmouth culter & Culter alburnus, Culter dabryi, Culter mongolicus \\
4 & Catfish & Pelteobagrus fulvidraco, Pelteobagrus eupogon, Silurus \\
asotus, etc.
\end{tabular}




$$
-6985-
$$

\section{Parameter settings}

\section{Yangtze finless porpoise}

The biomass of Yangtze finless porpoise was obtained according to the population census data in the reserve in 2015 . The $\mathrm{P} / \mathrm{B}$ coefficient and $\mathrm{Q} / \mathrm{B}$ coefficient refer to the setting coefficient of other ECOPATH models and the harbor porpoise of the same family and close weight, respectively 0.02 and 15 (Nurhakim, 1979; Plaganyi and Butterworth, 2005).

Fish

The total biomass of fish was obtained from 2014 hydroacoustic and catch survey data. According to the results of the hydroacoustic survey (unpublished data), the volume density of fish in the Tian-E-Zhou Oxbow was $0.18 \mathrm{Ind} . / \mathrm{m}^{2}$, which was converted to $0.81 \mathrm{Ind} . / \mathrm{m}^{2}$ of biomass. The P/B value of fish is derived from the following formula (Beverton and Holt, 1957; Pauly, 1980):

$$
\begin{gathered}
F=Y / B \\
P / B=Z=F+M \\
M=K^{0.65} \times L_{\infty}{ }^{-0.279} \times T_{c}{ }^{0.463}
\end{gathered}
$$

$\mathrm{Y}$ and $\mathrm{B}$ represent catch and fish biomass, respectively. While $\mathrm{F}$ and $\mathrm{M}$ stand for fishing mortality and natural mortality, respectively, $\mathrm{K}$ is the parameter of the Von Bertalanffy growth equation, $\boldsymbol{L}_{\infty}$ and is the asymptotic value of the body length of the Von Bertalanffy growth equation, $\mathrm{K}$ and $\boldsymbol{L}_{\infty}$ are obtained by a FishBase database query. $\mathrm{T}$ is the average annual water temperature $\left({ }^{\circ} \mathrm{C}\right)$.

The Q/B coefficient of fish is obtained by the empirical formula of Palomares and Pauly (1998).

\section{Shrimp and crab}

The biomass $\mathrm{P} / \mathrm{B}$ and $\mathrm{P} / \mathrm{Q}$ values of shrimp and crab were referenced to freshwater lakes or reservoirs in the Yangtze River basin at the same latitude (Halfon et al., 1996; He et al., 2000; Christensen et al., 2000; Deng et al., 2014).

\section{Benthic and plankton}

The biomass of benthic fauna, zooplankton and phytoplankton was based on the 2011 survey data of aquatic organisms, averaging $14.03 \mathrm{t} / \mathrm{km}^{2}, 16.2 \mathrm{t} / \mathrm{km}^{2}$ and $32.4 \mathrm{t} / \mathrm{km}^{2}$, respectively. The $\mathrm{P} / \mathrm{B}$ and $\mathrm{Q} / \mathrm{B}$ coefficients were obtained by referring to results from other lakes at the same latitude or by estimating the P/Q coefficients (Yan and Liang, 2003; Liu et al., 2007; Zeng et al., 2011).

\section{Detritus}

Detritus includes both bacterial and organic detritus, and the bacterial biomass is estimated at $17.5 \%$ of the phytoplankton biomass according to Heymans et al. (2004), and this result can be used generally. The biomass of organic debris was estimated by referring to the linear model proposed by Pauly et al. (1993). 


\section{Model debugging}

Because the ECOPATH model builds a steady-state system model, the energy flow budget for each functional group must be balanced. First, ecological nutrition efficiency $\mathrm{EE}=($ feed intake + catch $) /$ production. The sum of predation and catch in a functional group should be greater than 0 and less than its production, so $0<\mathrm{EE}<1$. The EE value of the functional group under high predation or fishing pressure in the system can be close to 1. Some underutilized functional groups usually have low EE values. Second, the respiration rate of each functional group must be greater than 0 , and the R/B coefficient (the ratio of respiration rate to biomass) of fish should be between 1 and 10. Finally, the $\mathrm{P} / \mathrm{Q}$ coefficient of the functional group represents the ratio of production to consumption, which is generally distributed between 0.1 and 0.3 in ecology, but may be less than 0.1 for some vegetative functional groups. When running the ECOPATH model, if these conditions are not met, the model cannot achieve balance or will lack the necessary biological significance. The researcher can then repeatedly adjust other input parameters in an appropriate range of settings, such as $\mathrm{B}, \mathrm{P} / \mathrm{B}$, or $\mathrm{Q} / \mathrm{B}$, and the composition of food, to find the equilibrium that has the actual meaning of the optimized parameter values while debugging steps of the specific reference (Christensen et al., 2008).

\section{Result}

\section{Model output parameters and ecological significance}

After the ECOPATH food web model of the Tian-E-Zhou Oxbow ecosystem had been balanced from 2011 to 2014, its basic parameters were summarized in Table 2. Since the biomass accumulation and migration of each functional group were all 0 in this study, the ecological nutrient conversion efficiency EE reflects the degree to which the production of each functional group is utilized by predation and fishing. It can be seen from Table 2 that the EE values of channa Argus, silver carp, and bighead ranged from 0.769 to 0.831 , indicating that they were highly utilized, which was consistent with the annual catch of the oxbow. The EE value of small pelagic fish was 0.823 , mainly due to the influence of the feeding pressure of the Yangtze Finless porpoise. The EE value of zooplankton was as high as 0.918 , which was related to silver carp and bighead. Phytoplankton, large aquatic plants, and detritus were not utilized to a high degree (EE values were $0.21,0.35$, and 0.035 , respectively).

\section{Overall features of the Tian-E-Zhou Oxbow ecosystem}

The total system throughput (TST) of the aquatic ecosystem of Tian-E-Zhou Oxbow was $19271.490 \mathrm{t} / \mathrm{km}^{2} /$ year, the total production (TP) of the system was $8977 \mathrm{t} / \mathrm{km}^{2} /$ year, and the total primary productivity (TPP) was $8486.625 \mathrm{t} / \mathrm{km}^{2} /$ year, accounting for $94.53 \%$ of the total production (Table 3).

The ratio of total primary productivity (TPP) to total respiration (TR) of the system (TPP/TR) is an important indicator of system maturity. Generally, the value of TPP/TR in a mature ecosystem is close to 1 , while TPP/TR $>1$ in a developing system. TPP/TR $<1$ for systems exposed to organic pollution (Odum, 1971). The TPP/TR=18.131 (Table 3) indicates that the Tian-E-Zhou Oxbow ecosystem is still a developing system.

The connection index (CI) and System omnivory index (SOI) are indicators of the complexity of the connections within an ecosystem, and the CI and SOI are higher, meaning that the system within the greater the chance of a variety of nutrients can be 
reused. The ecosystem is a more stable and mature system of CI index between the functional groups, and the SOI index value is close to 1 (Odum, 1971; Christensen, 1995). The CI and SOI indices of the Tian-E-Zhou Oxbow were 0.267 and 0.262 (Table 3), respectively, indicating that the degree of aggregation and stability among the functional groups of the ecosystem was low.

Table 2. Input and output parameters for the ECOPATH model of Tian-E-Zhou Oxbow

\begin{tabular}{c|c|c|c|c|c|c|c}
\hline Functional group & $\begin{array}{c}\text { Trophic } \\
\text { level }\end{array}$ & $\begin{array}{c}\text { Biomass } \\
\left(\mathbf{t} / \mathbf{k m}^{\mathbf{2}} \mathbf{)}\right.\end{array}$ & $\begin{array}{c}\text { Yield } \\
\mathbf{( t ~ k m}^{\mathbf{2}} \mathbf{)}\end{array}$ & $\begin{array}{c}\mathbf{P} / \mathbf{B} \\
\left(\mathbf{y e a r}^{-\mathbf{1}} \mathbf{)}\right.\end{array}$ & $\begin{array}{c}\mathbf{Q} / \mathbf{B} \\
\left(\mathbf{y e a r}^{-1} \mathbf{)}\right.\end{array}$ & $\mathbf{E E}$ & $\mathbf{P} / \mathbf{Q}$ \\
\hline Finless porpoise & 3.627 & 0.138 & & 0.020 & 15.000 & & 0.001 \\
Snakehead fish & 3.619 & 0.320 & 0.200 & 0.760 & 4.180 & 0.831 & 0.182 \\
Topmouth culter & 3.610 & 0.870 & 0.530 & 0.990 & 4.470 & 0.623 & 0.221 \\
Catfish & 3.548 & 0.440 & 0.310 & 1.990 & 9.030 & 0.501 & 0.220 \\
Common carp & 2.833 & 0.740 & 0.180 & 1.520 & 9.540 & 0.556 & 0.159 \\
Crucian carp & 2.308 & 0.680 & 0.250 & 2.100 & 7.000 & 0.729 & 0.300 \\
Small pelagic fish & 2.596 & 2.840 & & 1.600 & 15.000 & 0.823 & 0.107 \\
Small bottom fish & 2.649 & 2.100 & 0.200 & 2.300 & 17.390 & 0.763 & 0.132 \\
Silver carp & 2.500 & 5.200 & 4.500 & 1.090 & 13.600 & 0.805 & 0.080 \\
Bighead carp & 3.000 & 7.500 & 7.400 & 1.630 & 8.970 & 0.769 & 0.182 \\
Bluntnose bream & 2.006 & 0.190 & 0.110 & 1.530 & 10.830 & 0.449 & 0.141 \\
Other fish & 2.130 & 0.140 & 0.090 & 2.100 & 10.600 & 0.404 & 0.198 \\
Shrimp and Crabs & 2.537 & 1.510 & 0.15 & 3.500 & 20.000 & 0.785 & 0.175 \\
Zoobenthos & 2.481 & 14.030 & & 3.400 & 8.000 & 0.680 & 0.425 \\
Zooplankton & 2.111 & 16.200 & & 25.000 & 130.000 & 0.918 & 0.192 \\
Phytoplankton & 1.000 & 32.400 & & 260.000 & & 0.210 & \\
Macrophyte & 1.000 & 50.100 & & 1.250 & & 0.350 & \\
Detritus & 1.000 & 7.670 & & & & 0.035 & \\
\hline
\end{tabular}

Note: Estimated parameters in bold by model, P-production, B-biomass, Q-consumption

Table 3. Global ecosystem properties in Tian-E-Zhou Oxbow

\begin{tabular}{c|c|c|c}
\hline Parameter & Value 1 & Value 2 & Unit \\
\hline Sum of all consumption, TC & 2492.185 & 2493.220 & $\mathrm{t} / \mathrm{km}^{2} /$ year \\
Sum of all exports, TEX & 8018.562 & 8018.355 & $\mathrm{t} / \mathrm{km}^{2} /$ year \\
Sum of all respiratory flows, TR & 468.064 & 468.270 & $\mathrm{t} / \mathrm{km}^{2} /$ year \\
Sum of all flows into detritus, TDET & 8292.676 & 8292.470 & $\mathrm{t} / \mathrm{km}^{2} /$ year \\
Total system throughput, TST & 19271.490 & 19272.311 & $\mathrm{t} / \mathrm{km}^{2} /$ year \\
Sum of all production, TP & 8977 & 8977.001 & $\mathrm{t} / \mathrm{km}^{2} /$ year \\
Total net primary production, TPP & 8486.625 & 8486.625 & \\
Total primary production/total biomass, TPP/TB & 62.679 & 62.647 & \\
Total primary production/total respiration, TPP/TR & 18.131 & 18.123 & \\
Total biomass, TB & 135.398 & 135.467 & $\mathrm{t} / \mathrm{km}^{2} /$ year \\
Connectance index, CI & 0.267 & 0.267 & \\
System omnivory index, SOI & 0.262 & 0.260 & \\
Finn's cycling index, FCI & 2.48 & 2.48 & $\%$ \\
Finn's mean path length, FML & 2.271 & 2.271 & \\
\hline
\end{tabular}

Note: V1 is means the current status of the system (2011-2015); V2 is means the status at ecological carrying capacity for the Yangtze finless porpoise. The calculation method of all parameters is based on Christensen et al. (2005) 
Finn's circulation index (FCI) is the ratio of the circulation flow to the total flow in the system, and Finn's average path length (FML) is the average length of each cycle through the food chain. The higher the proportion of material recycling, and the longer the food chain through which the nutrient flow passes, the higher the system maturity (Christensen, 1995). The FCI and FML of the Tian-E-Zhou Oxbow ecosystem were $2.488 \%$ and 2.271 (Table 3), respectively, indicating that the water area had low material and energy recirculation ratio, short flow path, and the system was in the early stage of development.

\section{Nutrient-level structure and material energy flow of the Tian-E-Zhou Oxbow ecosystem}

The trophic levels of each functional group in the Ecosystem of Tian-E-Zhou Oxbow were divided into 7 discrete trophic levels (Table 4). It can be seen from the table that detritus and two primary producers completely occupy the nutritive grade I. The vegetative or omnivorous consumer functional group mainly occupied the trophic level II and III, among which zooplankton completely occupied the trophic levels II. Carnivorous fish and the functional group of the Yangtze finless porpoise mainly occupied the III and IV nutritional grades, and a small amount occupied the V and VI nutritional grades; the trophic level was completely dominated by the Yangtze finless porpoise. According to the specific flow distribution of each discrete trophic level, the nutrients in the Ecosystem of Tian-E-Zhou Oxbow mainly flowed between the first five discrete trophic levels. The traffic for the VI and traffic VII nutrition levels was very low, less than $1 \%$, and can be ignored.

Table 4. Trophic level decomposition of the functional groups in Tian-E-Zhou Oxbow ecosystem

\begin{tabular}{|c|c|c|c|c|c|c|c|}
\hline \multirow{2}{*}{ Functional group } & \multicolumn{7}{|c|}{ Trophic level } \\
\hline & I & II & III & IV & $\mathrm{V}$ & VI & VII \\
\hline Finless porpoise & & & 0.484 & 0.474 & 0.0387 & 0.00280 & 0.000022 \\
\hline Snakehead fish & & & 0.526 & 0.383 & 0.0861 & 0.00491 & 0.000019 \\
\hline Topmouth culter & & & 0.506 & 0.440 & 0.0529 & 0.00183 & \\
\hline Catfish & & & 0.590 & 0.338 & 0.0723 & 0.000375 & \\
\hline Common carp & & 0.400 & 0.447 & 0.137 & 0.0167 & & \\
\hline Crucian carp & & 0.780 & 0.163 & 0.0565 & 0.000833 & & \\
\hline Small pelagic fish & & 0.480 & 0.503 & 0.0167 & & & \\
\hline Small bottom fish & & 0.500 & 0.416 & 0.0832 & 0.000833 & & \\
\hline Silver carp & & 0.550 & 0.450 & & & & \\
\hline Bighead carp & & 0.100 & 0.900 & & & & \\
\hline Bluntnose bream & & 0.995 & 0.00500 & & & & \\
\hline Other fish & & 0.900 & 0.0833 & 0.0167 & & & \\
\hline Shrimp and Crabs & & 0.600 & 0.317 & 0.0833 & & & \\
\hline Zoobenthos & & 0.667 & 0.333 & & & & \\
\hline Zooplankton & & 1.000 & & & & & \\
\hline Phytoplankton & 1.000 & & & & & & \\
\hline Macrophyte & 1.000 & & & & & & \\
\hline Detritus & 1.000 & & & & & & \\
\hline
\end{tabular}

The total flow of a trophic level is the sum of the flux of all substances flowing through it per unit time. The total capacity of each trophic level is affected by respiration, arrests, food intake, catches, and the amount of debris. The transfer efficiency of each trophic 
level is equal to the ratio of the sum of its food intake and catch to the total flow, indicating the efficiency of utilization of the trophic level in the ecosystem. The energy flow process among different trophic levels in the Tian-E-Zhou Oxbow is shown in Fig. 2. Trophic level I includes phytoplankton and detrital functional groups, so the energy flow process of the Tian-E-Zhou Oxbow ecosystem can be divided into the grazing food chain and the detrital food chain. After the two food chains were merged, the transfer efficiency of trophic levels II, III, IV, V, VI, and the two food chains in the Tian-E-Zhou Oxbow ecosystem, in turn, were $9.0 \%, 11.9 \%, 11 \%, 10.9 \%, 10.2 \%$, and $5.3 \%$, respectively, with a total average conversion efficiency of $10.5 \%$ (Table 5).
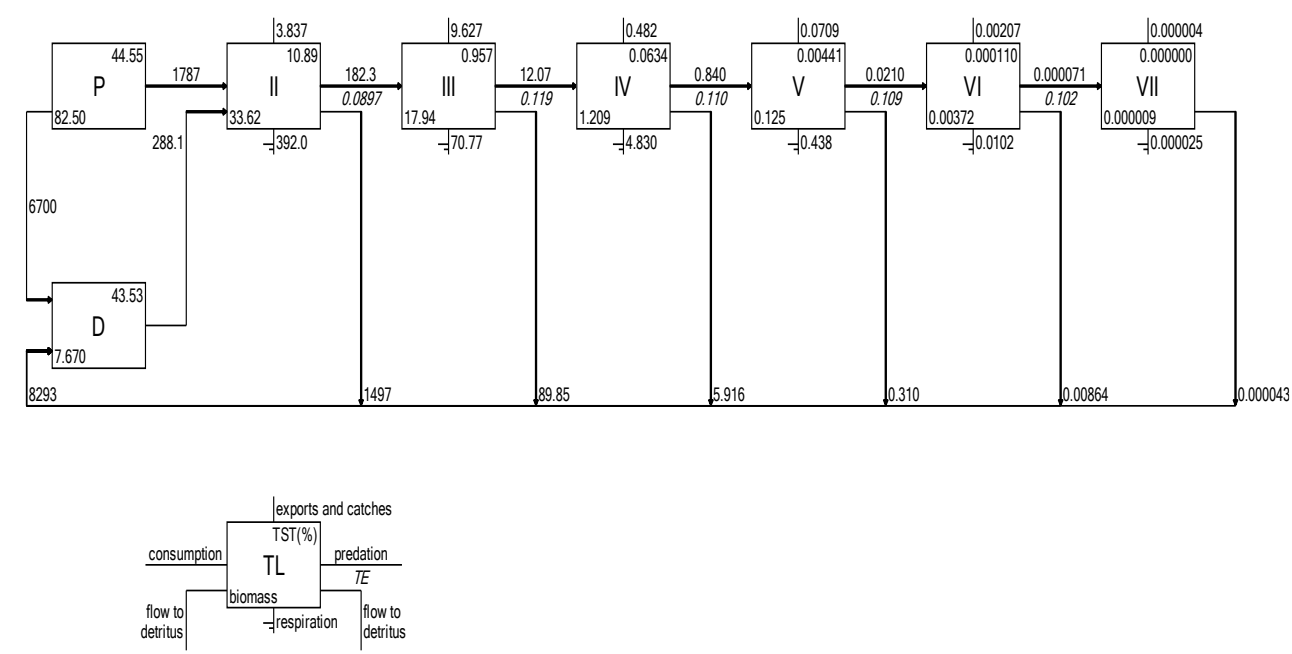

Figure 2. Trophic flows transferred along trophic levels in Tian-E-Zhou Oxbow ecosystem

Table 5. Transfer efficiencies among trophic levels in Tian-E-Zhou Oxbow ecosystem (\%)

\begin{tabular}{c|c|c|c|c|c|c}
\hline \multirow{2}{*}{ Source } & \multicolumn{5}{c}{ Trophic level } \\
\cline { 3 - 7 } & II & III & IV & V & VI & VII \\
\hline Producer & 8.7 & 11.9 & 11.0 & 11.0 & 10.2 & \\
Detritus & 10.8 & 11.7 & 11.0 & 10.8 & 10.1 & \\
All flows & 9.0 & 11.9 & 11.0 & 10.9 & 10.2 & 5.3 \\
\hline \multicolumn{7}{c}{ The energy from the debris shows a flow proportion: 0.45} \\
Detrital pathway conversion efficiency: $11.2 \%$ \\
Total conversion efficiency: $10.5 \%$ \\
\hline
\end{tabular}

\section{The carrying capacity of the Yangtze finless porpoise in the Tian-E-Zhou Oxbow}

The Yangtze finless porpoise is the top predator of the Tian-E-Zhou Oxbow ecosystem and a major conservation target of the Reserve. As the population continues to grow, it may cause a significant change in the energy flow of the Tian-E-Zhou Oxbow ecosystem. According to the definition of the carrying capacity in this study, when the population of the Yangtze finless porpoise in the ecosystem gradually increases, the predation pressure on its food resources is bound to increase, resulting in EE greater than 1. Then, the ecosystem is destroyed, and the model is out of balance. At present, the population is the carrying capacity of the Tian-E-Zhou Oxbow. In the iterative process, the biomass 
(population number) of the finless porpoise continuously increased. When it increased to $0.207 \mathrm{t} / \mathrm{km}^{2}$, the model was not balanced. At this time, EE $>1$ in the upper-middle and upper small fish functional groups was $>1$ (Table 6). Therefore, it is estimated that the average biomass of the finless porpoise supported by the Tian-E-Zhou Oxbow ecosystem is $0.207 \mathrm{t} / \mathrm{km}^{2}$ (about 89 individuals).

Table 6. Changes in Tian-E-Zhou Oxbow ECOPATH model while estimating the carrying capacity of Yangtze finless porpoise

\begin{tabular}{c|c|c|c}
\hline Frequency & $\begin{array}{c}\text { The biomass of the Yangtze finless } \\
\text { porpoise }\left(\mathbf{t} / \mathbf{k m}^{\mathbf{2}}\right)\end{array}$ & $\begin{array}{c}\text { EE of Small pelagic } \\
\text { fish }\end{array}$ & $\begin{array}{c}\text { Changes in the } \\
\text { model }\end{array}$ \\
\hline 1 & 0.138 & 0.823 & Balance \\
2 & 0.148 & 0.838 & Balance \\
3 & 0.158 & 0.874 & Balance \\
4 & 0.168 & 0.900 & Balance \\
5 & 0.178 & 0.926 & Balance \\
6 & 0.188 & 0.952 & Balance \\
7 & 0.198 & 0.977 & Balance \\
8 & 0.208 & 1.003 & No balance \\
9 & 0.207 & 1.001 & No balance \\
10 & 0.206 & 0.998 & Balance \\
\hline
\end{tabular}

\section{Discussion}

The Tian-E-Zhou Oxbow was originally the channel of the Yangtze River, which naturally curved and straightened. It was seasonally connected to the Yangtze River; however, after the completion of the Tian-E-Zhou Oxbow floodgate in 1998 (Fig. 1), it was cut off from the Yangtze River, so its ecosystem features are similar to lakes or small reservoirs. Due to the lack of large aquatic plants, the total flow was only $62.62 \mathrm{t} / \mathrm{km}^{2}$ year $^{-1}$, which was much lower than the total flow of phytoplankton $\left(8424 \mathrm{t} / \mathrm{km}^{2}\right.$ year $^{-1}$ ) (Fig. 2). Because the biomass of herbivorous fish is very small, the primary producer of the grazing food chain in the Tian-E-Zhou Oxbow ecosystem is the phytoplankton. However, the detrital food chain is also a significant energy flow channel, and the detrital energy flow accounts for $45 \%$ of the total flow of the system. In Fig. 2, we found that the total amount of organisms flowing into the debris of the biological chain finally reached $8290 \mathrm{t} / \mathrm{km}^{2}$ year ${ }^{-1}$, indicating that there was still a large quantity of nutrients left in the Tian-E-Zhou Oxbow ecosystem. This nutrient load has caused the deposition of a large amount of unused debris at the bottom of the water body, increasing the endogenous pollution and resulting in a nutrient excess and the emergence of a large amount of phytoplankton. The main fish species, including free-range silver carp, bighead, and a large number of silver carp, are caught every year. It can also be seen from Fig. 2 that the output of nutrient grades II $\left(3.837 \mathrm{t} / \mathrm{km}^{2}\right.$ year $\left.^{-1}\right)$ and III $\left(9.627 \mathrm{t} / \mathrm{km}^{2} \mathrm{year}^{-1}\right)$ is the largest, and they are the main exporters.

According to the ecosystem development described by Odum (1971) and Christensen (1995), TPP/TR is $>1$ in the immature ecosystem and will approach 1 when the ecosystem becomes mature. The Ecopath model has been constructed for many lakes to assess the maturity of aquatic ecosystems. The TPP/TR ratio was 18.13 in the Tian-E-Zhou Oxbow ecosystem (Table 3). This ratio was higher than that of most lakes in China, including Shangshe, Gehu, Dianchi, Chaohu, Taihu (Jia et al., 2012; Li et al., 2013, 2019; Shan et 
al., 2014; Kong et al., 2016). That may because the Tian-E-Zhou Oxbow was cut off with Yangtze River in 1998 and belongs to a relatively young lake.

The average conversion efficiency of the general ecosystem was approximately $10 \%$ (Lindeman, 1942), while the conversion efficiency between the trophic levels of the Tian-E-Zhou Oxbow ecosystem was $10.5 \%$ (Table 5), which is relatively close. However, the conversion efficiency between grade I and grade II in primary producers is low $(8.7 \%)$ (Table 5), which may be due to a suboptimal proportion of silver carp and bigheads, resulting in a loose connection between functional groups. On the one hand, the filter pressure of silver carp on phytoplankton is low; on the other hand, the pressure of bighead, which is large, is high, which leads to less feeding of phytoplankton by the bighead, which will lead to the overgrowth of phytoplankton which cannot be fully utilized, and there is the risk of "bloom". Therefore, it is suggested that the stocking ratio of silver carp and bighead in the Tian-E-Zhou Oxbow should be adjusted to a level that is beneficial to the stability of the ecosystem.

By improving the conversion efficiency of residual nutrients and the ecosystem characteristics of the Tian-E-Zhou Oxbow, the aim is to improve the habitat quality of the Yangtze finless porpoise and expand the carrying capacity of the oxbow to accommodate the porpoise and protect the population more effectively. In this study, the carrying capacity of the Tian-E-Zhou Oxbow for the finless porpoise was $0.207 \mathrm{t} / \mathrm{km}^{2}$, accounting for about 89 individuals (Table 6). According to this study (Table 2), the biomass of the small fish is the main factor affecting the carrying capacity of the habitat for the finless porpoise.

The carrying capacity is a fundamental feature of wildlife conservation biology that influenced by many factors. For example, in aquatic ecosystems, the primary productivity of the animal habitat determines the amount of plant growth available, and plant growth is under the influence of various physical and chemical factors in the water (Hobbs et al., 1985). The availability of plants is closely related to the limitation of the mobility of aquatic animals (Hobbs et al., 1982). The efficiency determines the primary consumers of resources, layer upon layer, top determines the number of consumers. The purpose of estimating the carrying capacity of the Tian-E-Zhou Oxbow for the Yangtze finless porpoise is to determine the capacity of the system from the perspective of energy balance. The ECOPATH model itself does consider the biological growth changes at each trophic level; it only takes fixed parameter values and does not take into account the spatial changes. Therefore, there is still a shortage of biological variables, such as life history. The carrying capacity is a process of dynamic change that can be influenced by both population and habitat changes of species. Therefore, dynamic changes that cannot be described by the static model need to be considered when calculating the carrying capacity. However, the estimation method of carrying capacity used in this study can provide a referential calculation method for the selection of future protected areas, which can help determine the carrying capacity of ex-situ reserves for the Yangtze finless porpoise.

\section{Conclusion}

In this study, a food web model of the Tian-E-Zhou oxbow ecosystem was developed based on the EwE modeling framework. The aim is to use the model to estimate the ecological carrying capacity of the Tian-E-Zhou oxbow ecosystem for the Yangtze finless porpoise. The model shows that the material and energy recycling was low, together with 
a low connectance index (CI), system omnivory index (SOI), Finn's cycled index, and Finn's mean path length, indicating that the Tian-E-Zhou ecosystem is an immature ecosystem and still at its development stage. Finally, based on the ECOPATH model, the carrying capacity of the Tian-E-Zhou reserve for Yangtze finless porpoise was $0.207 \mathrm{t} / \mathrm{km}^{2}$, accounting for about 89 individuals. The ecological capacity of target species in the Tian-E-Zhou ecosystem is determined on the basis of mass balance, without further consideration for spatial changes and life history. The set of parameters used to determine the ecological carrying capacity is one of the possible parameter combinations that can achieve similar results. This model is open for further improvement. In addition, DNA barcoding for prey identification or a combination of DNA-barcoding and stable isotope analyses may further elucidate the energy flow of the Tian-E-Zhou ecosystem as well as enable proper evaluation of the carrying capacity of Tian-E-Zhou reserve for the Yangtze finless porpoise.

Acknowledgements. This work was supported by grants from the Special Fund for Agro-scientific Research in the Public Interest of the Ministry of Agriculture of China (No. 201203086-08). We sincerely thank all staff of Tian-E-Zhou ex situ reserves. We also thank Captain Zeliang Ding for their valuable help during data collection, and thank Yujiang Hao and Zhigang Mei for their participation in our experimental design and analysis. All authors declare no conflict of interests.

\section{REFERENCES}

[1] Behera, P. R., Parida, P. K., Karna, S. K., Raman, R. K., Suresh, V. R., Behera, B. K., Das, B. K. (2020): Trophic fingerprinting of Chilika, a Ramsar site and the largest lagoon of Asia using Ecopath. - Regional Studies in Marine Science 37: 101328.

[2] Beverton, R. J., Holt, S. J. (1957): On the dynamics of exploited fish populations. - Fishery Investigations, Series II, 19. London: Her Majesty's Stationary Office.

[3] Byron, C., Link, J., Costa-Pierce, B., Bengtson, D. (2011): Calculating ecological carrying capacity of shellfish aquaculture using mass-balance modeling: Narragansett Bay, Rhode Island. - Ecological Modelling 222(10): 1743-1755.

[4] Chapman, E. J., Byron, C. J. (2018): The flexible application of carrying capacity in ecology. - Global Ecology and Conservation 13: e00365.

[5] Christensen, V. (1995): Ecosystem maturity - towards quantification. - Ecological modelling 77(1): 3-32.

[6] Christensen, V., Walters, C. J., Pauly, D. (2000): Ecopath with Ecosim: a user's guide, October 2000 Edition. - Fisheries Centre, University of British Columbia, Vancouver, Canada and ICLARM, Penang, Malaysia, 130.

[7] Christensen, V., Walters, C. J. (2004): Ecopath with Ecosim: methods, capabilities and limitations. - Ecological modelling 172(2-4): 109-139.

[8] Christensen, V., Walters, C. J., Pauly, D. (2005): Ecopath with Ecosim: a user's guide. Fisheries Centre, University of British Columbia, Vancouver, 154.

[9] Christensen, C. J., Silberberg, A., Hursh, S. R., Roma, P. G., Riley, A. L. (2008): Demand for cocaine and food over time. - Pharmacology Biochemistry and Behavior 91(2): 209216.

[10] Deng, H. T., Duan, X. B., Liu, S. P., Chen, D. Q. (2014): Temporal and spatial variations in the trophic structure of key species in downstream of the Daning River. - Acta Ecologica Sinica 34(23): 7110-7118.

[11] Edwards, R. Y., Fowle, C. D. (2013): The concept of carrying capacity. - Essential Readings in Wildlife Management and Conservation 34: 279-293. 
[12] Ferreira, J. G., Corner, R. A., Moore, H., Bricker, S. B., Rheault, R. (2018): Ecological Carrying Capacity for Shellfish Aquaculture - Sustainability of Naturally Occurring FilterFeeders and Cultivated Bivalves. - Journal of Shellfish Research 37(4): 709-726.

[13] Finn, J. T. (1976): Measures of ecosystem structure and function derived from analysis of flows. - Journal of theoretical Biology 56(2): 363-380.

[14] Gao, Y., Fang, J., Lin, F., Li, F., Li, W., Wang, X., Zhang, Y. (2020): Simulation of oyster ecological carrying capacity in Sanggou Bay in the ecosystem context. - Aquaculture International 28(5): 2059-2079.

[15] Guo, C., Ye, S., Lek, S., Liu, J., Zhang, T., Yuan, J., Li, Z. (2013): The need for improved fishery management in a shallow macrophytic lake in the Yangtze River basin: Evidence from the food web structure and ecosystem analysis. - Ecological modelling 267: 138-147.

[16] Halfon, E., Schito, N., Ulanowicz, R. E. (1996): Energy flow through the Lake Ontario food web: conceptual model and an attempt at mass balance. - Ecological Modelling 86(1): $1-36$.

[17] He, ZH. H. (2000): Freshwater Ecology. - China Agriculture Press

[18] Heymans, J. J., Shannon, L. J., Jarre, A. (2004): Changes in the northern Benguela ecosystem over three decades: 1970s, 1980s, and 1990s. - Ecological modelling 172(2-4): 175-195.

[19] Hobbs, N. T., Baker, D. L., Ellis, J. E., Swift, D. M., Green, R. A. (1982): Energy-and nitrogen-based estimates of elk winter-range carrying capacity. - The Journal of Wildlife Management 5: 12-21.

[20] Hobbs, R. J. (1985): Harvester ant foraging and plant species distribution in annual grassland. - Oecologia 67(4): 519-523.

[21] Jia, P., Hu, M., Hu, Z., Liu, Q., Wu, Z. (2012): Modeling trophic structure and energy flows in a typical macrophyte dominated shallow lake using the mass balanced model. Ecological Modelling 233: 26-30.

[22] Kong, X., He, W., Liu, W., Yang, B., Xu, F., Jørgensen, S. E., Mooij, W. M. (2016): Changes in food web structure and ecosystem functioning of a large, shallow Chinese lake during the 1950s, 1980s and 2000s. - Ecological Modelling 319: 31-41.

[23] Leopold, A. (1933): Game management. - Wildlife of Mexico: the game birds and mammals.

[24] Leopold, A. (1987): Game management. - Univ. of Wisconsin Press.

[25] Li, Y., Song, B., Chen, Y., Chen, L., Yu, N., Olson, D. (2010): Changes in the trophic interactions and the community structure of Lake Taihu (China) ecosystem from the 1960s to 1990s. - Aquatic ecology 44(2): 337-348.

[26] Li, C., Wang, Q., Ye, S., Huang, G., Liu, J., Li, Z. (2018): Modeling trophic structure and energy flows in a shallow lake, Yangtze River Basin, China: a case analysis for culturebased fishery practices. - Aquaculture Environment Interactions 10: 213-226.

[27] Lindeman, R. L. (1942): The trophic-dynamic aspect of ecology. - Ecology 23(4): 399417.

[28] Liu, Q. G., Chen, Y., Li, J. L., Chen, L. Q. (2007): The food web structure and ecosystem properties of a filter-feeding carps dominated deep reservoir ecosystem. - Ecological Modelling 203(3-4): 279-289.

[29] Ma, X. J., Shen, J. Z., Wang, T., Wang, H. S., Huang, D., Sun, G. W., Gong, C. (2014): Macrozoobenthos community structure and water quality evaluation of Tian-E-Zhou Oxbows. - Huanjing kexue 35(10): 3952-3958.

[30] Nurhakim, S. (2003): Marine fisheries resources of the north coast of central Java, Indonesia: an ecosystem analysis. - Assessment, Management, and Future Directions for Coastal Fisheries in Asian Countries 6: 299-312.

[31] Odum, E. P., Barrett, G. W. (1971): Fundamentals of ecology. - Cengage Learning, Inc.

[32] Outeiro, L., Byron, C., Angelini, R. (2018): Ecosystem maturity as a proxy of mussel aquaculture carrying capacity in Ria de Arousa (NW Spain): A food web modeling perspective. - Aquaculture 496: 270-284. 
[33] Palomares, M. L. D., Pauly, D. (1998): Predicting food consumption of fish populations as functions of mortality, food type, morphometrics, temperature and salinity. - Marine and freshwater research 49(5): 447-453.

[34] Pauly, D. (1980): On the interrelationships between natural mortality, growth parameters, and mean environmental temperature in 175 fish stocks. - ICES journal of Marine Science 39(2): 175-192.

[35] Pauly, D., Christensen, V. (1993): Stratified models of large marine ecosystems: a general approach and an application to the South China Sea. Large marine ecosystems: stress, mitigation and sustainability. - AAAS Press, Washington, DC 11: 148-174.

[36] Plagányi, É. E., Butterworth, D. S. (2005): Indirect fishery interactions. - In: Reynolds, J. E., Perrin, W. F., Reeves, R. R., Montgomery, S., Ragen, T. J. (eds.) Marine Mammal Research: Conservation beyond Crisis. Baltimore, MD: John Hopkins University Press 8, pp. 19-46.

[37] Polovina, J. J. (1984): Model of a coral reef ecosystem. - Coral reefs 3(1): 1-11.

[38] Shan, K., Li, L., Wang, X., Wu, Y., Hu, L., Yu, G., Song, L. (2014): Modelling ecosystem structure and trophic interactions in a typical cyanobacterial bloom-dominated shallow Lake Dianchi, China. - Ecological modelling 291: 82-95.

[39] Storch, D., Okie, J. G. (2019): The carrying capacity for species richness. - Global Ecology and Biogeography 28(10): 1519-1532.

[40] Sun, G. W., Shen, J. Z., Hu, S. D., Gong, C., Wang, H. S., Huang, D. (2013): Age, growth and mortality of Pseudobrama simoni (Bleeker) in Tian-E-Zhou Oxbow of the Yangtze River. - Freshwater Fisheries 2013-04.

[41] Ulanowicz, R. E. (1986): NETWRK3: A package of Computer Algorithms to analyze ecological flow networks. - Chesapeake Biological Laboratory.

[42] Ulanowicz, R. E. (2012): Growth and development: ecosystems phenomenology. Springer Science \& Business Media.

[43] Wang, T., Wang, H. S., Sun, G. W., Huang, D., Shen, J. H. (2012): Length-weight and length-length relationships for some Yangtze River fishes in Tian-E-Zhou Oxbow, China. - Journal of Applied Ichthyology 28(4): 660-662.

[44] Yan, Y. J., Liang, Y. L. (2003): The energy flow of benthic fauna communities in The Bantam Pond. - Acta Ecologica Sinica 23(3): 527-538.

[45] Zeng, T. H., Liu, G. X., Hu, Z. Y. (2011): Estimation of phytoplankton primary production of lakes in the middle and lower reaches of the Yangtze River. - Resources and Environment in the Yangtza Basin 20(6): 717-722.

[46] Zhu, K., Wu, Y., Li, C., Xu, J., Zhang, M. (2020): Ecosystem-Based Restoration to Mitigate Eutrophication: A Case Study in a Shallow Lake. - Water 12(8): 2141. 